\title{
The effect of surface silanol groups on the deposition of apatite onto silica surfaces: a computer simulation study
}

\author{
D. Mkhonto · Nora H. de Leeuw
}

Received: 15 January 2006/Accepted: 31 May 2006/Published online: 28 June 2007

(C) Springer Science+Business Media, LLC 2007

\begin{abstract}
Computer modelling techniques were employed to investigate the effect of surface silanol groups on the strength of adhesion of apatite thin films to silica surfaces. To this end, we have studied a series of silica surfaces with different silanol densities and calculated their interaction with apatite thin films. Our findings indicate that apatite does not attach strongly to surface hydroxy groups, but that apatite should deposit at dehydrated silica surfaces, especially when the surface silicon and oxygen species rearrange to form $\mathrm{O}-\mathrm{Si}-\mathrm{O}$ links. Any dangling silicon and oxygen bonds at the silica surfaces are saturated by coordination to oxygen and calcium atoms in the apatite layer, but the extra reactivity afforded by these undercoordinated surface species does not necessarily lead to more favourable substrate/film interactions. The lowest energy silica/apatite interfaces are those where an undistorted apatite layer can be deposited on a regular, stable substrate surface. Our simulations support the suggestion, that in vivo surface hydroxy groups are first condensed to form $\mathrm{O}-\mathrm{Si}-\mathrm{O}$ bridges before deposition and growth of apatite.
\end{abstract}

D. Mkhonto · N. H. de Leeuw

School of Crystallography, Birkbeck College, Malet Street, London WC1E 7HX, UK

D. Mkhonto

Manufacturing and Materials Technology, Centre for Scientific and Industrial Research, P.O. Box 395, Pretoria 0001,

South Africa

N. H. de Leeuw $(\bowtie)$

Department of Chemistry, University College London, 20

Gordon Street, London WC1H 0AJ, UK

e-mail: n.h.deleeuw@ucl.ac.uk

\section{Introduction}

Since the discovery of the bio-compatible properties of Bioglass ${ }^{\circledR}$ revolutionized the field of bio-materials research [1], most investigations have concentrated on designing bio-active implant materials for hard tissue replacement, which resemble as closely as possible the structure and properties of natural bone. The mineral apatite is the major component of natural mammalian bone and tooth material and as such it may be a prime candidate for the manufacture of artificial bones [e.g. 2, 3]. However, the dense crystalline apatite material, although at the atomic level chemically and structurally equivalent to the mineral phase in bone, has very different mechanical properties from the apatitic phase in natural bone, for example the bending and compressive strengths and elastic constants [4], and it is difficult to shape [5, 6]. One way to still employ its excellent tissue response and osteoconductivity properties is to deposit an apatite layer onto a ceramic implant to promote integration of the implant with the natural bone [7]. For example, Kokubo and co-workers have found that bio-active ceramics, including glasses and glass-ceramics, bond to living bone through a collagen-free apatite layer [4], and formation of such an apatite layer on the synthetic material before implantation in the body thus encourages intergrowth with the living bone.

Alternatively, Bioglass ${ }^{\circledR}$ and other bio-active implant materials are used directly as they tend to dissolve in the body and to be resorbed into hard tissue, bonding to both bone and soft tissue. On implanting, the surface itself forms a biologically active apatite layer which provides the bonding interface with tissues, such as collagen and other proteins. The sequence of reactions leading to apatite layer formation on bio-active glasses, following immersion in tissue or body fluids is now thought to be reasonably well 
understood [8, 9]: Starting from the bulk bio-active glass, a silica rich layer is formed at the surfaces through segregation, where the surface hydroxy groups then form growth nuclei for the attachment of the apatite layer. However, Kokubo and co-workers found that in vitro quartz or silica glass does not induce apatite formation at its surface, whereas silica gel does [10]. They attribute the difference in activity towards apatite formation in these chemically similar materials to the different densities of $\mathrm{Si}-\mathrm{OH}$ groups in the three materials. The silica gel contains many more surface silanol groups than the glass or quartz crystal, which they suggest induces apatite formation. It is not entirely clear, however, whether the hydroxy groups attach to the apatite through hydrogen-bonding [4, 10, 11] or whether they first condense to $\mathrm{O}-\mathrm{Si}-\mathrm{O}$ bridges, via dissolution of $\mathrm{Si}(\mathrm{OH})_{4}$ species, which then form the sorption sites for the deposition of calcium and phosphate species [12].

Thus, as the precise nature of the attachment of the apatite layer to the implant is not known, whether it is attached before the implant is introduced into the body or whether grown in vivo, there is a clear need to gain an understanding of the interactions between the apatite and the ceramic substrate at the atomic level. The present work therefore reports a systematic computational study of the attachment of apatite films to silica surfaces, where we have concentrated in particular on the rôle of the surface silanol groups in the adhesion of the apatite layer and the resulting stabilities of the silica/apatite interfaces.

We have concentrated on $\alpha$-quartz as a model structure for a variety of silicate materials and silica-rich bio-active glasses, systematically choosing a range of different surface topologies to ensure that as far as possible the major substrate/film structures and interactions are investigated. We have used quartz as a substrate in this work, rather than a silica glass, because the use of a crystalline material allowed us to control the density and distribution of the surface silanol groups very accurately, which would be more approximate using a glassy material. As the subject of this paper was to quantify the effect of the surface silanol groups on the apatite film, we considered that the use of a crystalline material was acceptable as the interaction of the apatite with surface hydroxy groups and silicon species will be the same for both materials, only the spatial arrangement in the quartz will be more ordered than in a glass surface.

Our approach is to employ energy minimisation techniques to study the interactions of two thin film thicknesses of apatite with a range of silica surfaces, containing different surface densities of silanol groups. As we create and fully geometry-optimise the silica surfaces before attaching the apatite films, the calculated structures and energies of the silica/apatite interfaces are independent of the way in which the substrate surface was created, and this model should hence be applicable to both melt-derived and sol-gel derived bio-active glass surfaces.

\section{Methodology}

The computer modelling of hetero-interfaces and grain boundaries of ionic materials is still a new and little explored area of research, due to the complexity of the simulated systems and the difficulty of direct comparison with experiment. Apart from the simplest type of interface, where a single planar interface separates two otherwise perfect crystals of the same or different crystalline phase [13], more complex interfaces can also be considered, such as tilt interfaces where the two crystal surfaces are tilted with respect to each other at varying angles [14-16], or twist interfaces as studied in this work, where the two crystals are rotated relative to each other. Another factor to take into account when modelling solid/solid interfaces, or indeed when growing experimental thin films on substrate surfaces, is the epitaxial misfit between the substrate and the thin film parallel to the interface [17]. Sayle and coworkers have shown, for example, that a large epitaxial misfit may lead to significant reconstruction in the thin film, including reorientation of the thin film to express a different surface at the interface, the formation of extensive dislocations and even amorphisation of the thin film in extreme cases where the misfit between the crystal lattices is $20 \%$ or larger $[18,19]$. The interatomic potential-based techniques employed in this work are the most suitable techniques to investigate at the atomic level these solid/ solid interfaces between two complex materials, which necessitates large simulations cells containing thousands of ions. We have shown in earlier work that these methods can be used successfully to calculate at the atomic level the geometries and adhesion energies of solid/solid interfaces $[16,20,21]$ and we have therefore now employed the same energy minimisation techniques to investigate the effect of surface silanol groups on the strength of adhesion of the apatite layer.

These atomistic simulation methods are based on the Born model of solids [22], which assumes that the ions in the crystal interact via long-range electrostatic forces and short-range forces, including both the repulsions and the van der Waals attractions between neighbouring electron charge clouds. The long-range Coulombic interactions are calculated using the Parry technique [23, 24] (which is adapted from the well known Ewald method to 2D periodic systems) whereas the short-range forces are described by parameterised analytical expressions. The electronic polarisability of the ions is included via the shell model of Dick and Overhauser, where each polarisable ion is 
represented by a core and a massless shell, connected by a spring [25]. The polarisability of the model ion is then determined by the spring constant and the charges of the core and shell, which are usually obtained by fitting to experimental dielectric constants when available. In addition, it is often necessary to include angle-dependent forces to allow for directionality in partially covalent bonds, for instance in the silica groups and phosphate anion. We have employed established interatomic potential parameters for the silicate substrate [26-28] and recently developed potentials for apatite, which have been shown to be accurate in describing both bulk and surface properties of the material [29]. The potential parameters describing the interactions between the apatite film and silicate surface were derived following the well-established approach of Schroder et al. [30], and they have been used successfully in previous work on the interaction of apatite with silica $[20,21,31]$. The complete potential model is shown in Table 1.

We have used the METADISE computer simulation code for the calculation of the surface and interfacial structures and energies [14], which is designed specifically for the simulation of surfaces, interfaces and dislocations. As such, periodic boundary conditions are employed only in two directions in the plane of the surface/interface, whereas there is no periodic boundary in the direction perpendicular to the interface. This set up hence avoids undesirable interactions between surfaces/interfaces across a vacuum gap between repeating slabs, which is the more usual set up for the simulation of surfaces with threedimensional periodic boundary conditions. The interfacial systems are charge-neutral and no dipole is present perpendicular to the interface, in order to avoid nonconvergence of the energies with system size due to surface dipole effects [32].

Before energy minimisation of the interfacial system, the apatite film was kept at a constant height above the surface, but moved laterally with respect to the quartz surface without relaxation of the substrate or film, i.e. the apatite film would be moved systematically in two directions over the substrate surface and the interfacial energy for this unrelaxed system would be calculated for a series of points on a grid. The grid was determined by the surface lattice vectors of the system in two directions, and the interfacial energy was calculated at intervals of $1 \AA$. This scan thus supplied us with an interfacial energy at each point on the grid, hence identifying the lowest-energy lateral displacement of the film with respect to the substrate in the unrelaxed system, which was then taken as the starting point for our energy minimisation calculation of the substrate/film interface. Once the most energetically favourable initial lateral film/substrate orientation was thus identified, a full geometry optimisation was performed to
Table 1 Potential Parameters used in this work (short-range cutoff $20 \AA$ )

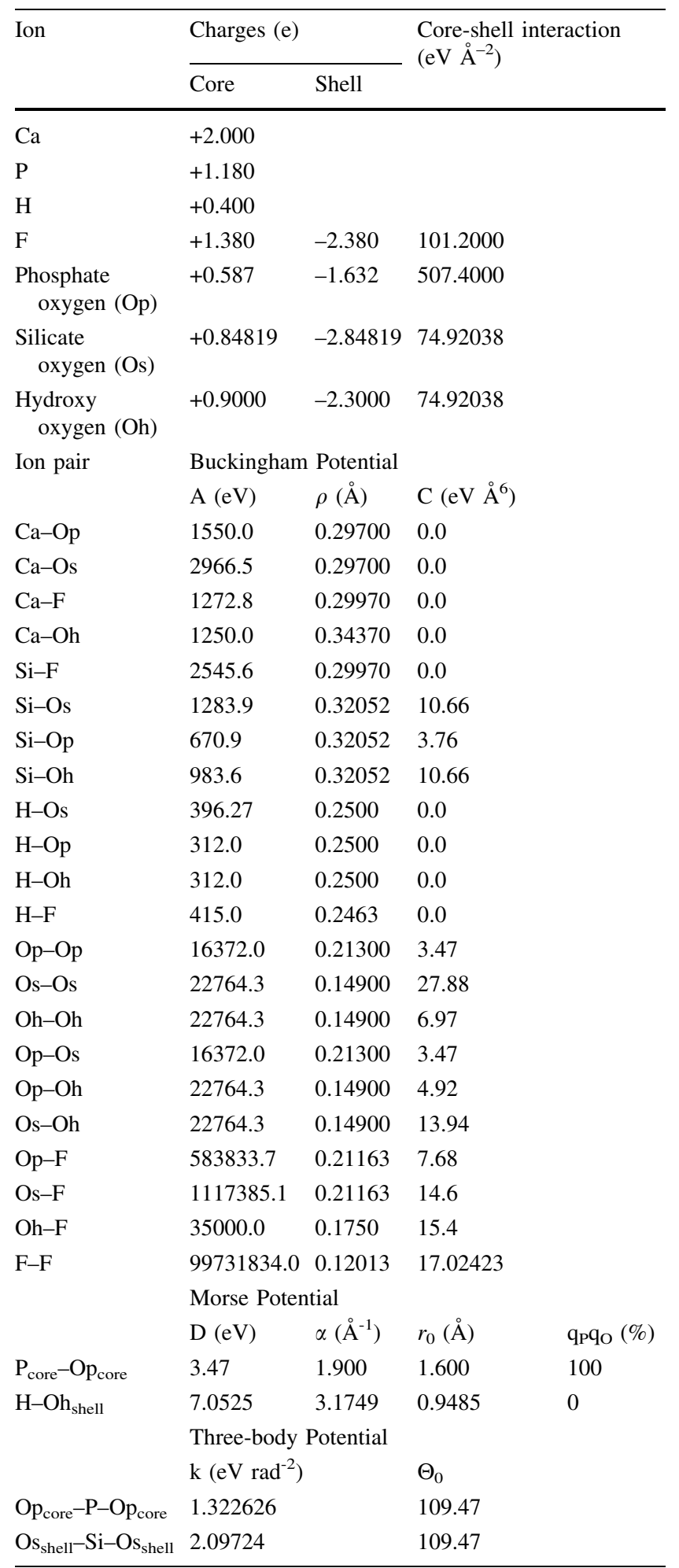

obtain the energy of the relaxed interfacial system, where the optimisation algorithm used is the Newton-Raphson variable matrix method, which takes into account not only 
the first derivative of the energy with respect to ion position, i.e. the forces on the ions during minimisation, but also the second derivative of the energy [33]. The initial height above the surface was varied in a series of calculations to check that this parameter did not affect the final energy and to ensure that the lowest energy configuration had been obtained. During geometry optimisation, not only was the apatite film free to move in any direction with respect to the underlying quartz surface, but all atoms in the apatite film and in a quartz surface region of about $22 \AA$ into the bulk material were also completely unconstrained so as not to prejudice the geometry of the interface. The complete process was then repeated for a series of rotations of the apatite thin film with respect to the quartz substrate and the adhesion energies calculated. We found that with this careful procedure, the lowest energy configurations for each rotated system were unambiguous with well-defined energy minima.

\section{Results and discussion}

In order to investigate the interactions between the apatite material and the silica surfaces, and especially the effect of the silanol groups, we have epitaxially fitted apatite films of two thicknesses to the substrate surface, scanned the films over the surface as described above, followed by full geometry optimisations. A series of rotations of the thin films with respect to each of the substrate surfaces as well as different lateral displacements ensure that a large number of film/substrate configurations is sampled, thus investigating a comprehensive range of interactions between the thin films and the substrate surfaces.

Apatite structure and chemistry

Apatites $\mathrm{Ca}_{10}\left(\mathrm{PO}_{4}\right)_{6}(\mathrm{~F}, \mathrm{Cl}, \mathrm{OH})_{2}$ are a complex and diverse class of materials, where the isomorphous series can be represented by fluorapatite $\mathrm{Ca}_{10}\left(\mathrm{PO}_{4}\right)_{6} \mathrm{~F}_{2}$, which is by far the most common, chlorapatite $\mathrm{Ca}_{10}\left(\mathrm{PO}_{4}\right)_{6} \mathrm{Cl}_{2}$, hydroxyapatite $\mathrm{Ca}_{10}\left(\mathrm{PO}_{4}\right)_{6}(\mathrm{OH})_{2}$ and carbonate-apatite $\mathrm{Ca}_{10}\left(\mathrm{PO}_{4}\right.$, $\left.\mathrm{CO}_{3}, \mathrm{OH}\right)_{6}(\mathrm{~F}, \mathrm{OH})_{2}$ [34], in addition to a range of less common substituted apatite materials [35 and references therein]. Whilst the natural bone mineral is closest in structure and chemistry to the hydroxy apatite, it still contains a significant number of defects and impurities, including carbonate defects, calcium vacancies and a number of substitutions for the hydroxy groups, where fluoride is especially important [2]. However, despite the impure nature of the apatitic phase in bone, it is still reasonably well described by the general apatite structure, which we have therefore employed in this work, opting for the use of the well-studied fluorapatite structure, where we can view the fluoride ions as a generic anion in the structure. Fluorapatite has a hexagonal crystal structure with spacegroup $\mathrm{P}_{3} / \mathrm{m}[34,36]$. The apatite structure is shown in Fig 1, where the $\mathrm{F}^{-}$ions in the structure are located one above the other in a hexagonal column parallel to the c-axis (into the plane of the paper in Fig. 1a). The fluoride ions in the hexagonal channels are coordinated to three calcium ions each in a triangular arrangement, where these calcium triangles are alternated along the c-direction, hence forming the hexagonal channel. For our simulations, we have used the structure determined by Hendricks et al. [37] with $a=b=9.370 \AA, \quad c=6.880 \AA$, where $\alpha=\beta=90^{\circ}$, $\gamma=120^{\circ}$, which upon energy minimisation of the bulk crystal relaxed to at $a=b=9.375 \AA, c=6.871 \AA$, $\alpha=\beta$ ? $=90^{\circ}, \gamma=120^{\circ}$. The calculated properties of the fluorapatite crystal, such as the structure, elastic and dielectric constants and phosphate vibrational modes, are in good agreement with experiment, as is fully discussed in reference [29].
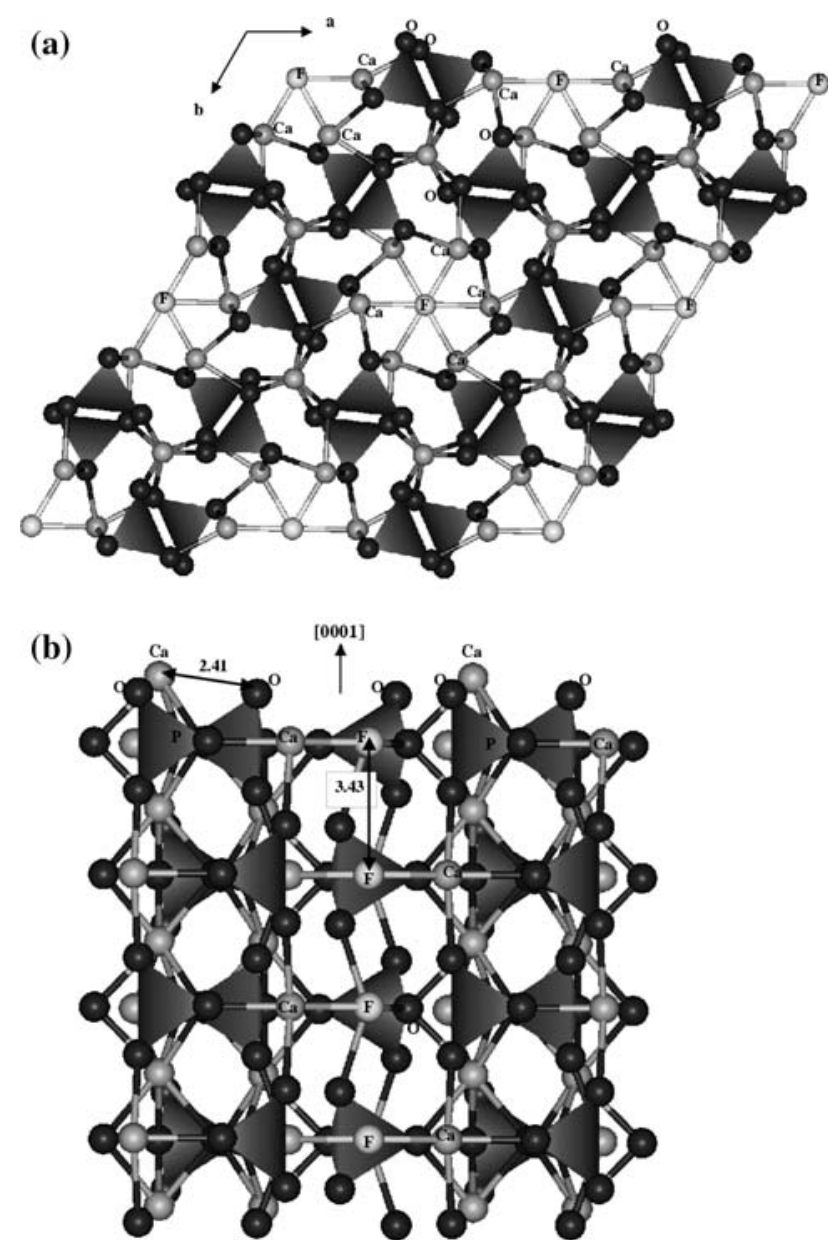

Fig. 1 The hexagonal fluorapatite structure, showing (a) plan view of the (0001) surface and (b) side view, showing the hexagonal channels $\left(\mathrm{Ca}=\right.$ mid grey, $\mathrm{O}=$ black, $\mathrm{F}=$ pale grey, $\mathrm{PO}_{4}$ groups displayed as tetrahedra) 
The structure of the silica substrate surfaces

We are primarily interested in the effect of the surface silanol groups on the adhesion of the apatite material and we have therefore first created a number of silica surface simulation cells with different surface silanol densities in a range of configurations. We have chosen the dominant quartz (0001) surface as the substrate surface, using a $(2 \times 2)$ surface supercell, for the adhesion of the apatite films, also in the (0001) orientation. $\alpha$-Quartz has lattice parameters of $a=b=4.913 \AA, c=5.404 \AA$, while the lattice parameters of fluorapatite are $a=b=9.370 \AA$, $c=6.880 \AA[34,37]$. As we are considering the growth of apatite thin films at existing substrate surfaces, the apatite films need to fit epitaxially to the substrate surfaces, and the film will thus necessarily be tensioned or contracted to accommodate itself to the quartz surface lattice vectors [13]. If we build a $(2 \times 2)$ simulation supercell of quartz, the apatite (0001) plane fits the quartz (0001) surface as a $(2 \times 2)$ overlayer with a lattice misfit of $-4.6 \%$, i.e. the apatite layer is tensioned to accommodate itself to the substrate surface.

The silica structure is built up of a network of cornersharing $\mathrm{SiO}_{4}$ tetrahedra with a $\mathrm{Si}-\mathrm{O}$ bond length of $1.61 \AA$ and $\mathrm{O}-\mathrm{Si}-\mathrm{O}$ angle equal to $109.3^{\circ}$. The quartz (0001) surface may simply be considered as a $\mathrm{SiO}_{2}$ network consisting of neutral or charged silanol groups $\left(\mathrm{SiOH}_{2}{ }^{+}\right.$, $\mathrm{SiOH}$ or $\mathrm{SiO}^{-}$), depending on the $\mathrm{pH}$ of the aqueous environment, where $\mathrm{SiOH}_{2}{ }^{+}$groups only occur under highly acidic conditions. (The concentration of $\mathrm{SiOH}_{2}{ }^{+}$ groups is found to be highest at $\mathrm{pH}=0$ [38]). When the silica surface is created from the bulk material, it contains under-coordinated silicon atoms which are bonded to three oxygen atoms (Q3 sites) as well as singly coordinated surface oxygen atoms, where the surface density of Q3 sites is $5 \mathrm{~nm}^{-2}$. These under-coordinated surface sites are shown in Fig. 2(a $+b)$ from the side and as a plan view, for clarity showing only the first two surface layers of the quartz crystal. Under highly alkaline conditions, these dangling bonds would remain unprotonated and our simulations show that on geometry optimisation the dangling bonds rearrange in the surface to form $\mathrm{O}-\mathrm{Si}-\mathrm{O}$ bridges in the surface, thus increasing the coordination of the surface silicon and oxygen atoms to the stable bulkcoordination numbers of four and two, respectively. The relaxed (0001) surface is hence built up of six-rings of Si and $\mathrm{O}$ atoms in the surface plane, which is shown in Fig. 2(c $+d)$.

Under less alkaline conditions, the dangling bonds become protonated, forming $-\mathrm{SiOH}$ groups at the surface, and the resulting structure for the fully protonated surface is shown in Fig. 3, where dissociated water molecules are adsorbed to the surface adding an $\mathrm{OH}^{-}$group to the dangling bonds of each Q3 Si and a proton to each singlycoordinated $\mathrm{O}$ atom, resulting in each surface $\mathrm{Si}$ atom becoming coordinated to two oxygen atoms in the bulk material and two $\mathrm{OH}$ groups at the surface. However, the maximum concentration of surface $-\mathrm{SiOH}$ groups is found
Fig. 2 The $\alpha$-quartz surfaces with $\mathrm{SiO}^{-}$species, (a) side-view of the unoptimised bulkterminated (0001) surface, and (b) plan view of the top two layers of the unoptimised bulkterminated (0001) surface, showing dangling bonds; (c) side view and (b) plan view of the top surface layer, showing the formation $\mathrm{O}-\mathrm{Si}-\mathrm{O}$ bridges into surface 6-ring structures ( $\mathrm{Si}=$ pale grey, $\mathrm{O}=$ black)

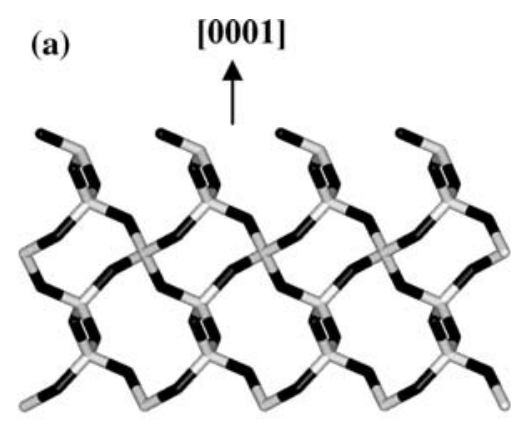

(b)

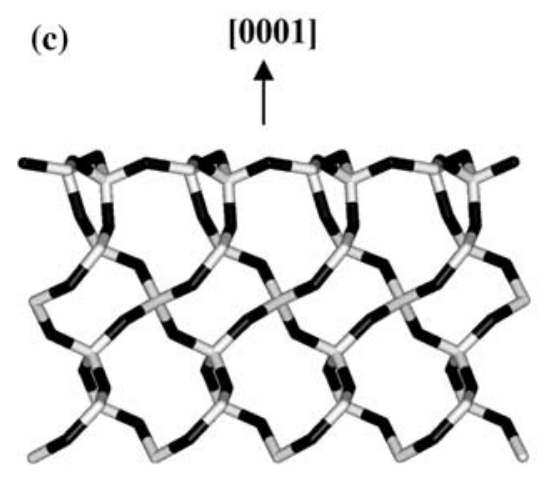

(d)

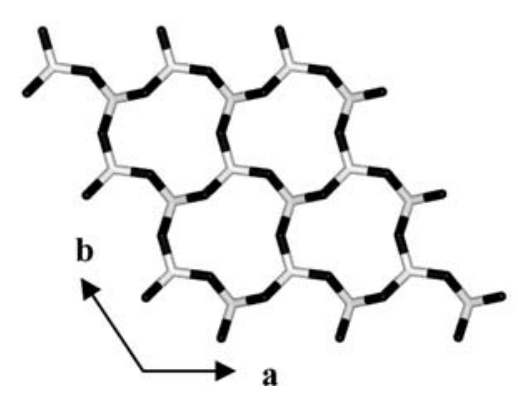


Fig. 3 Side and plan views of the fully protonated $\alpha$-quartz (0001) surface, showing surface silanol groups, (a) side view and (b) plan view of the top two layers of the (0001) surface $(\mathrm{Si}=$ pale grey, $\mathrm{O}=$ black, $\mathrm{H}=$ white, silanol groups displayed as balls)

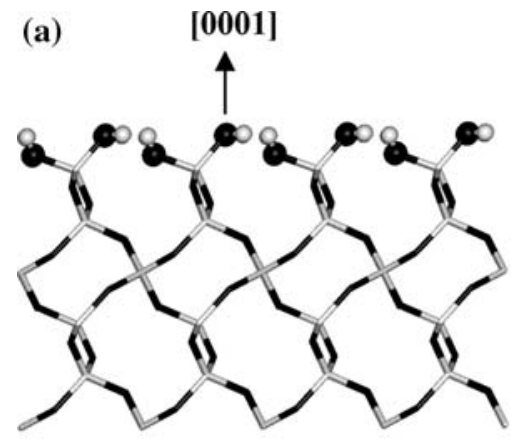

(b)

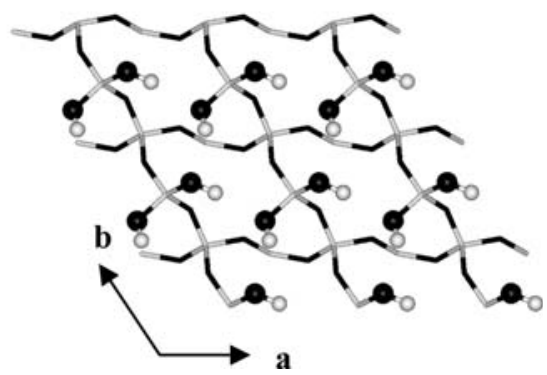

under slightly acidic conditions, at $\mathrm{pH}=6$ [38], and as the $\mathrm{pH}$ of the body is about $\mathrm{pH}=7.4$, upon implantation in vivo some of the silica surface species will remain protonated as $-\mathrm{SiOH}$ groups, but the more alkaline environment will also lead to a proportion of silanol groups becoming deprotonated to form $-\mathrm{SiO}^{-}$species, which then would either remain as dangling bonds or form O-Si-O bridges if the geometry of the surface permits. Clearly the adhesion of apatite may well be different whether the silica surface is fully protonated, fully deprotonated or in an intermediate configuration. We have therefore not only studied the completely deprotonated surface and the surface fully covered by silanol groups, but also a number of intermediate cases of 25,50 and $75 \%-\mathrm{SiOH}$ coverage, taking into account the different geometries that can be obtained for each coverage. As each Q3 Si site leads to two surface silanol groups, the surface densities of the silanol groups at the silica surfaces considered in this work are thus $0,2.5,5,7.5$ and $10 \mathrm{~nm}^{-2}$, covering the range of $\mathrm{pH}=6$ to $\mathrm{pH} \geq 8$ [38].

Melt-derived bio-active glasses are thought to have a network connectivity of two in order to be bio-active, whereas our surfaces have an initial network connectivity of three. However, although the surface silicon atoms are initially bonded to two bonding oxygen atoms into the bulk material and one non-bonded oxygen atom, after protonation the dangling bond of the non-bonded oxygen atom has been saturated by a proton and as a result, the surface silicon species have become bonded to two hydroxy oxygen atoms each (Fig. 3). Q2 surface silicon species with two dangling bonds will be highly reactive and, whether in vitro or in vivo, will almost instantaneously attract water to saturate these dangling bonds. As a result, the Q2 Si species will also become bonded to two surface hydroxy groups, in much the same way as our initial Q3 surfaces and we would therefore expect that the processes described here will also apply to Q2 surfaces.

The simulation cell of the fully protonated silica surface contains eight hydroxy groups at the surface, and we created the partially protonated surfaces by removing water molecules from the surface according to the following process:

$-\mathrm{Si}(\mathrm{OH})_{2} \rightarrow-\mathrm{SiO}+\mathrm{H}_{2} \mathrm{O}$

where $-\mathrm{Si}(\mathrm{OH})_{2}$ is the hydroxylated surface silica species and $\mathrm{SiO}$ is the deprotonated surface silica species. The consecutive removal of three water molecules from the fully protonated surface thus created 75, 50 and $25 \%$ protonated surfaces with 6, 4 and 2 hydroxy groups per simulation cell, respectively (shown in Fig. 4). For the $50 \%$ protonated surface, there are a number of possible geometries of the hydroxy groups at the surface and the lowest energy geometry is shown in Fig. 4b, which is mainly used for further calculations of apatite attachment.

The $25 \%$ protonated surface, shown in Fig. 4 a has become rather distorted compared to the 0 and $100 \%$ protonated surfaces, shown in Fig. $2 \mathrm{~d}$ and $3 \mathrm{~b}$ respectively. Most dangling bonds at the surface have rearranged to form $\mathrm{O}-\mathrm{Si}-\mathrm{O}$ bridges, but one three-coordinated $\mathrm{Si}$ atom remains together with one dangling oxygen bond. On the $50 \%$ protonated surface all dangling bonds have rearranged to increase the coordination of surface $\mathrm{Si}$ and $\mathrm{O}$ atoms to their bulk coordination. The lowest energy configuration, shown in Fig. 4b, then consists of rows of hydroxy groups interspersed with rows of fully coordinated deprotonated $\mathrm{Si}$ and $\mathrm{O}$ atoms in $\mathrm{O}-\mathrm{Si}-\mathrm{O}$ bridges. It is the regularity of this surface geometry which makes this particular configuration the most stable of the $50 \%$ protonated surfaces. Finally, when $75 \%$ of the surface is protonated, shown in Fig. 4(c), the surface simulation cell contains one three-coordinated $\mathrm{Si}$ atom and one oxygen dangling bond, which cannot form any $\mathrm{O}-\mathrm{Si}-\mathrm{O}$ bridges as the neighbouring species are all protonated and hence already fully coordinated.

Apatite/Silica interfaces

We first studied the attachment of two apatite film thicknesses to the completely deprotonated silica surface, comprising the surface six-rings made up of $\mathrm{O}-\mathrm{Si}-\mathrm{O}$ 
(a)

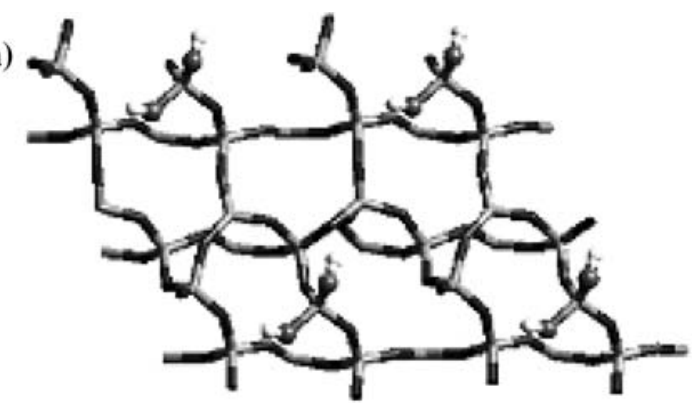

(b)
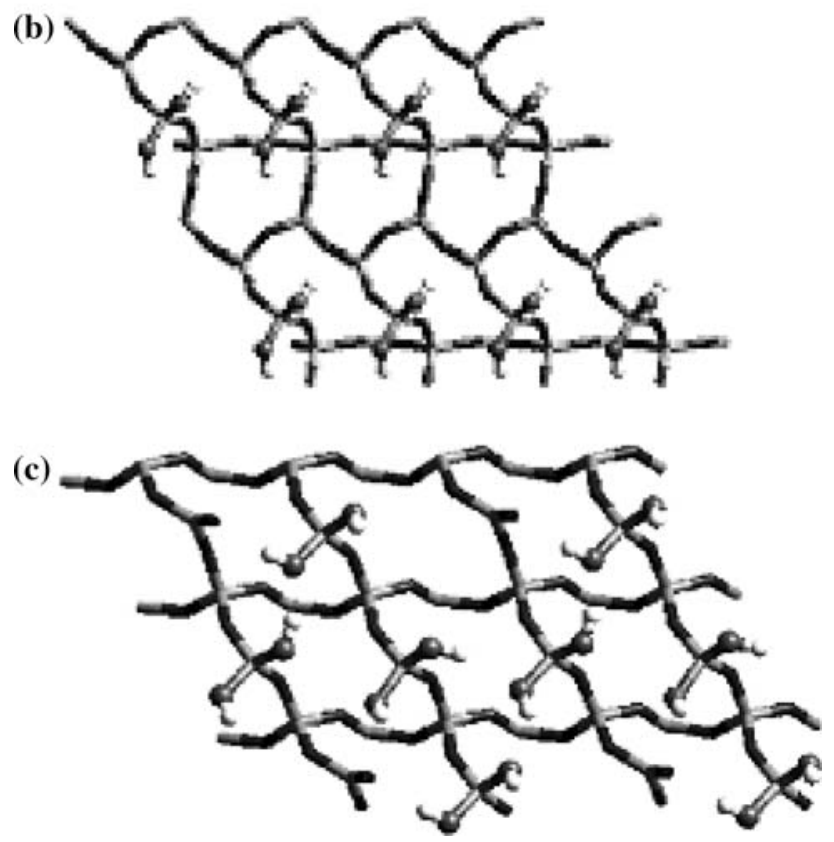

Fig. 4 Plan views of the partially protonated silica surfaces, showing the lowest energy configurations of (a) $25 \%$, (b) $50 \%$ and (c) $75 \%$ coverages of silanol groups $(\mathrm{Si}=$ pale grey, $\mathrm{O}=$ black, $\mathrm{H}=$ white, silanol groups displayed as balls)

bridges (Fig. $2 \mathrm{c}+\mathrm{d}$ ). As described in section 2.0, the apatite film is brought down upon the substrate and laterally scanned over the substrate surface to identify the energetically preferential lateral orientation of the interface as a starting configuration, followed by a full geometry optimisation of the complete system containing both substrate and apatite film. The final structure of the interface is shown in Fig. 5(a), where we see that the structure of the quartz surface has not altered significantly upon adhesion of the apatite film. The apatite interacts with the silica surface through its calcium ions and oxygen atoms, but the substrate's silicon and oxygen atoms retain their four- and two-fold coordination in the $\mathrm{O}-\mathrm{Si}-\mathrm{O}$ surface 6-rings, rather than form direct bonds to the apatite thin film. The interactions which are formed between the quartz surface and the apatite film are therefore fairly weak as they are over and beyond the normal coordination number of the oxygen and silicon atoms in the substrate, with much longer
$\mathrm{Si}-\mathrm{O}_{\text {apatite }}(\geq 2.02 \AA)$ and $\mathrm{Ca}-\mathrm{O}_{\text {quartz }}(\geq 2.52 \AA)$ distances than in normal $\mathrm{Si}-\mathrm{O}(\sim 1.6 \AA)$ and $\mathrm{Ca}-\mathrm{O}(\sim 2.4 \AA)$ bonds. The interface in general has a regular structure, without mixing of the two materials, and the apatite film resembles the bulk crystal. There is a distinct interfacial gap of 2.03$2.16 \AA$ wide, depending on the rotation of the apatite film with respect to the substrate, which is measured as the distance in the c-direction only between an apatite $\mathrm{Ca}$ atom and a quartz $\mathrm{Si}$ atom.

We next investigated the interface of the apatite thin films with the fully protonated surface with a surface density of silanol groups of $10 \mathrm{~nm}^{-2}$. This time the apatite film can only interact with the oxygen and hydrogen atoms in the silica surface as the silicon atoms are obscured by the hydroxy groups. As such, the two materials are kept together by a number of hydrogen-bonding interactions between the silanol hydrogen atoms and oxygen ions in the apatite films (OH- $\mathrm{O}_{\text {apatite }}$ distances between 1.92 and $2.28 \AA$, depending on the rotation of the apatite film), but without any interactions between surface $\mathrm{Si}$ and $\mathrm{O}$ atoms to apatite $\mathrm{O}$ and $\mathrm{Ca}$ atoms. Again, the structure of the apatite film is hardly affected by the substrate, as is shown in Fig. 5(b), and not surprisingly the interfacial gap between the topmost $\mathrm{Si}$ atoms and the bottommost $\mathrm{Ca}$ atom is wider at 2.49-3.42 $\AA$, depending on the rotation of the apatite film.

Having first studied the interfaces of the apatite thin films with the fully protonated and completely deprotonated silica surfaces, we next considered the formation of apatite films at the partially protonated substrates to investigate whether the density of surface silanol groups affects the structure and strength of the interface. As could perhaps be expected of an interface formed at a surface containing both silanol groups and unprotonated oxygen atoms, the apatite film interacts with the substrate both via hydrogen-bonding through its oxygen ions as well as by its $\mathrm{Ca}$ ions to the (under-coordinated) oxygen atoms of the silica surface. The different substrate/film interactions per simulation cell are summarised in Tables 2, 3 and for the single and double apatite layers, respectively. We first describe the interfaces of the single apatite film on the silica substrates.

On the surface with $75 \%$ protonation of the surface oxygen atoms (density of silanol groups $=7.5 \mathrm{~nm}^{-2}$ ), the lowest energy interface at a rotation of $120^{\circ}$ (Fig. 6a) shows that an apatite calcium ion forms a strong bond with the singly-coordinated silica oxygen atom $\left(\mathrm{Ca}-\mathrm{O}_{\text {silica }}=\right.$ $2.19 \AA$ ), hence saturating its dangling bond. There are further non-bonded interactions between $\mathrm{Ca}$ and hydroxy oxygen atoms $\left(\mathrm{Ca}-\mathrm{O}_{\text {silica }}=3.57 \AA\right)$ and hydrogen-bonded interactions at $\mathrm{H}-\mathrm{O}_{\text {apatite }}=2.13-2.21 \AA$.

As described above, the most stable $50 \%$ protonated surface with a silanol density of $5.0 \mathrm{~nm}^{-2}$ does not contain oxygen dangling bonds or three-coordinated silicon atoms 
Fig. 5 Apatite films on deprotonated and fully protonated quartz surfaces, (a) single and double layer of apatite attached to the deprotonated surface and (b) single layer of apatite attached to the fully protonated quartz surface $(\mathrm{Ca}=$ mid grey, $\mathrm{O}=$ black, $\mathrm{F}=$ pale grey, $\mathrm{PO}_{4}$ groups displayed as tetrahedra, $\mathrm{Si}=$ pale grey, $\mathrm{O}=$ black, $\mathrm{H}=$ white, closest $\mathrm{Si}-\mathrm{O}_{\text {apatite, }}$, $\mathrm{Ca}-\mathrm{O}_{\text {silica }}$ and $\mathrm{H}-\mathrm{O}_{\text {apatite }}$ distances drawn in) (a)
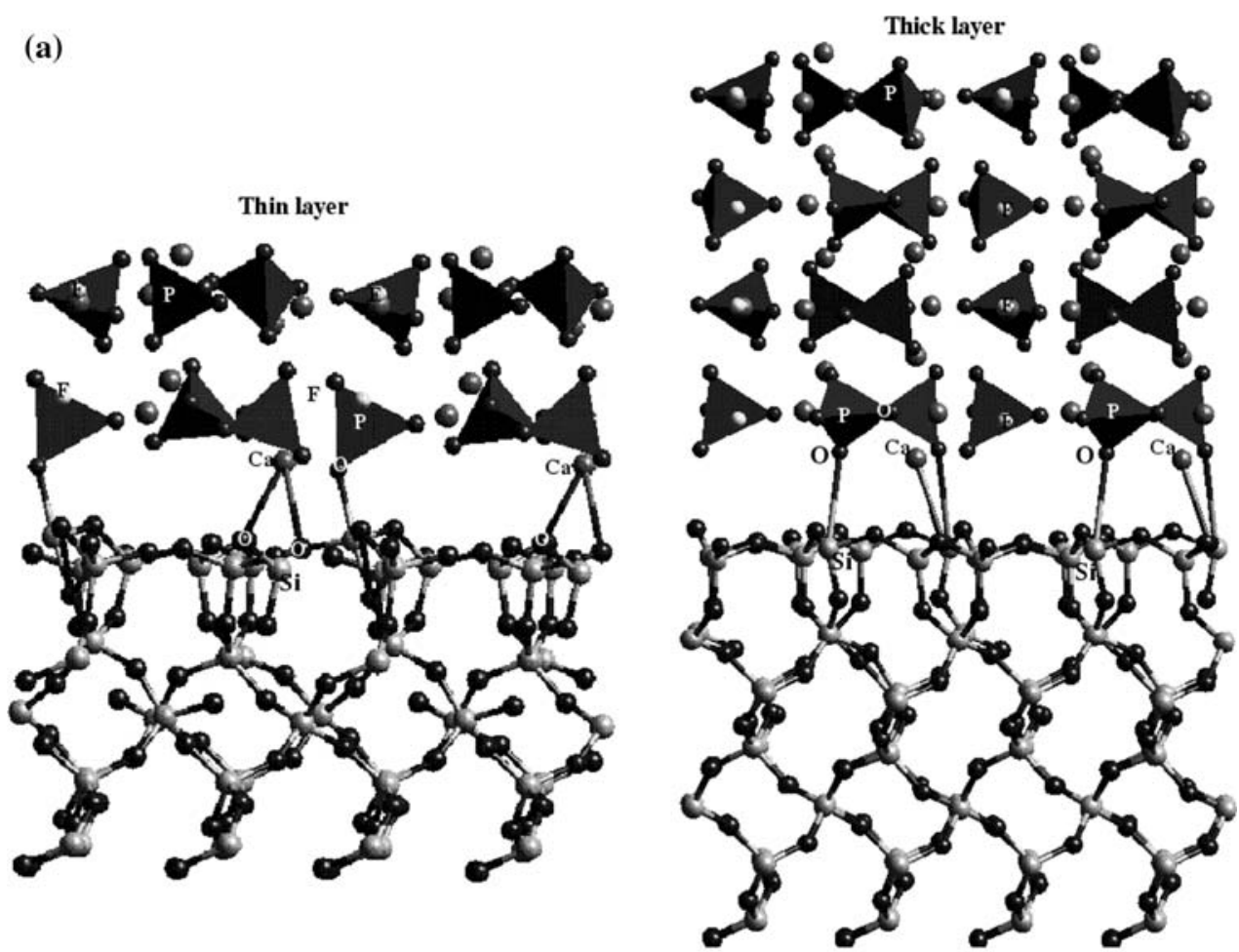

(b)

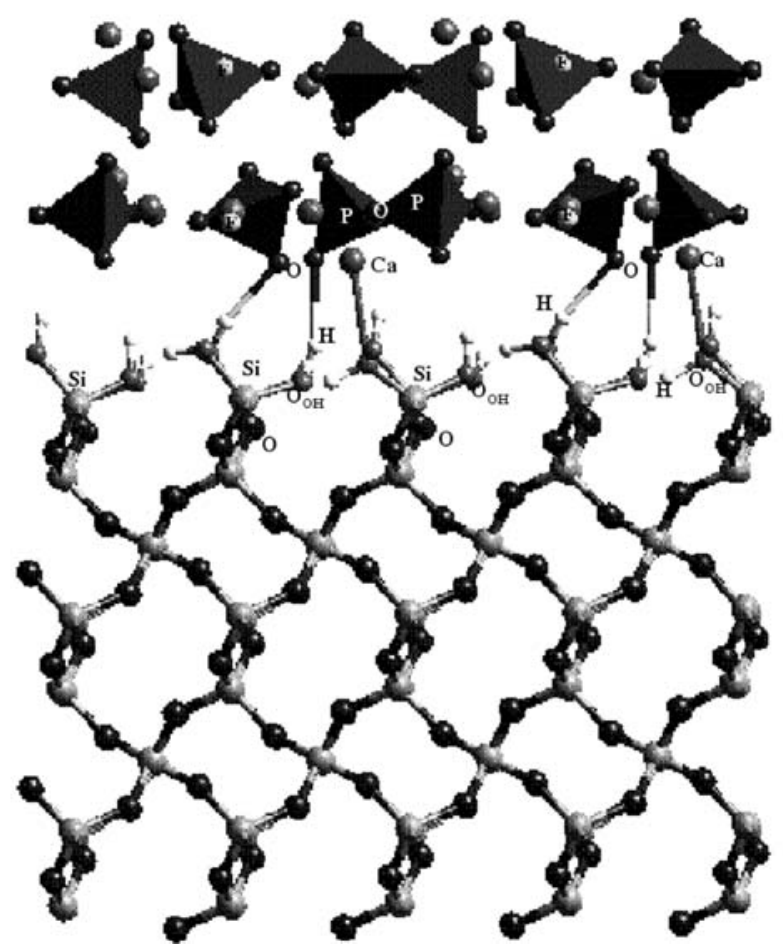

as rearrangement of these species in the surface has saturated their coordination. The adhesion of the apatite thin film to this surface (shown in its lowest energy $120^{\circ}$ rotation in Fig. 6b) is therefore mainly through hydrogenbonding to the apatite oxygen atoms at 1.87-1.97 $\AA$ and the interaction between $\mathrm{Ca}$ atoms and silica oxygens is weak (closest $\mathrm{Ca}-\mathrm{O}_{\text {silica }}=3.00 \AA$ ). However, on this substrate we also find interactions between apatite fluoride ions and hydrogen atoms of the hydroxy groups, although these only occur at the energetically less preferred rotations, not the most stable interface of $120^{\circ}$ rotation as shown in Fig. 6(b), and the interactions are weak (Table 2). 
Table 2 Interatomic distances at different rotations of the interface between a single layer of apatite and silica surfaces containing different concentrations of surface silanol groups

\begin{tabular}{|c|c|c|c|c|c|}
\hline \multicolumn{6}{|c|}{ Interatomic distances $(\AA)$} \\
\hline$\%$ surface $\mathrm{OH}$ & Rotation $^{\circ}$ & $\mathrm{Ca}-\mathrm{O}_{\text {silica }}$ & $\mathrm{Ca}-\mathrm{O}_{\mathrm{OH}}$ & $\mathrm{H}_{\mathrm{OH}}-\mathrm{O}_{\text {apatite }}$ & \\
\hline \multirow[t]{7}{*}{75} & $0 / 360$ & 2.20 & 3.44 & $2.12,2.14$ & \\
\hline & 60 & 2.19 & 3.60 & $2.25,2.29,2.35$ & \\
\hline & 120 & 2.19 & 3.57 & $2.13,2.17,2.21$ & \\
\hline & 180 & 2.23 & 3.39 & $2.01,2.03,2.06$ & \\
\hline & 240 & 2.20 & 3.59 & $2.05,2.20,2.27$ & \\
\hline & 300 & 2.22 & 3.68 & $2.10,2.30,2.43$ & \\
\hline & & $\mathrm{Ca}-\mathrm{O}_{\mathrm{q}}$ & $\mathrm{Ca}-\mathrm{O}_{\mathrm{OH}}$ & $\mathrm{H}_{\mathrm{OH}}-\mathrm{O}_{\mathrm{A}}$ & $\mathrm{F}-\mathrm{H}$ \\
\hline \multirow[t]{7}{*}{50} & $0 / 360$ & 2.96 & 3.06 & $2.24,2.28$ & 2.92 \\
\hline & 60 & 3.96 & 3.13 & $2.14,2.48$ & \\
\hline & 120 & 3.63 & $3.0,3.09$ & $1.87,1.97$ & \\
\hline & 180 & 4.34 & $2.69,3.04$ & $2.11,2.30$ & 3.45 \\
\hline & 240 & 2.96 & 3.15 & $2.24,2.28$ & 2.92 \\
\hline & 300 & 3.82 & $2.64,3.16$ & $2.03,2.24$ & 3.25 \\
\hline & & $\mathrm{Ca}-\mathrm{O}_{\mathrm{q}}$ & $\mathrm{Ca}-\mathrm{O}_{\mathrm{OH}}$ & $\mathrm{H}_{\mathrm{OH}}-\mathrm{O}_{\mathrm{A}}$ & $\mathrm{Si}-\mathrm{O}_{\mathrm{A}}$ \\
\hline \multirow[t]{6}{*}{25} & $0 / 360$ & 2.23 & 3.75 & $2.63,2.82$ & - \\
\hline & 60 & 2.22 & 4.09 & 1.95 & - \\
\hline & 120 & 2.27 & 3.57 & $1.75,2.69$ & 1.78 \\
\hline & 180 & 2.22 & 3.99 & 1.91 & - \\
\hline & 240 & $2.47,2.51$ & 3.05 & 1.98 & 1.74 \\
\hline & 300 & 2.22 & 4.09 & 1.95 & \\
\hline
\end{tabular}

Table 3 Interatomic distances at different rotations of the interface between a double layer of apatite and silica surfaces containing different concentrations of surface silanol groups

\begin{tabular}{|c|c|c|c|c|c|}
\hline \multicolumn{6}{|c|}{ Interatomic distances $(\AA)$} \\
\hline$\%$ surface $\mathrm{OH}$ & Rotation $^{\circ}$ & $\mathrm{Ca}-\mathrm{O}_{\text {silica }}$ & $\mathrm{Ca}-\mathrm{O}_{\mathrm{OH}}$ & $\mathrm{H}_{\mathrm{OH}}-\mathrm{O}_{\text {apatite }}$ & \\
\hline \multirow[t]{7}{*}{75} & $0 / 360$ & 2.15 & 3.63 & $2.05,2.28,2.40$ & \\
\hline & 60 & 2.22 & 3.35 & $1.84,2.08,2.28$ & \\
\hline & 120 & 2.14 & 3.58 & $2.46,2.47$ & \\
\hline & 180 & 2.22 & 3.81 & $1.84,2.09,2.28$ & \\
\hline & 240 & 2.15 & 3.63 & $2.05,2.28,2.53$ & \\
\hline & 300 & 2.22 & 3.35 & $1.84,2.09$ & \\
\hline & & $\mathrm{Ca}-\mathrm{O}_{\mathrm{q}}$ & $\mathrm{Ca}-\mathrm{O}_{\mathrm{OH}}$ & $\mathrm{H}_{\mathrm{OH}}-\mathrm{O}_{\text {apatite }}$ & \\
\hline \multirow[t]{7}{*}{50} & $0 / 360$ & 2.15 & 3.63 & $2.05,2.28,2.40$ & \\
\hline & 60 & $2.64,2.72$ & 3.03 & $2.06,2.20$ & \\
\hline & 120 & 3.80 & $2.60,2.97$ & $1.98,2.31$ & \\
\hline & 180 & 2.78 & $2.71,2.85$ & $2.00,2.18$ & \\
\hline & 240 & 2.72 & 2.77 & $2.03,2.04,2.20$ & \\
\hline & 300 & $2.71,2.78$ & 2.85 & $2.00,2.18,2.43$ & \\
\hline & & $\mathrm{Ca}-\mathrm{O}_{\mathrm{q}}$ & $\mathrm{Ca}-\mathrm{O}_{\mathrm{OH}}$ & $\mathrm{H}_{\mathrm{OH}}-\mathrm{O}_{\text {apatite }}$ & $\mathrm{Si}-\mathrm{O}_{\text {apatite }}$ \\
\hline \multirow[t]{6}{*}{25} & $0 / 360$ & 2.19 & 3.86 & 2.07 & - \\
\hline & 60 & 2.19 & 3.96 & 1.92 & - \\
\hline & 120 & $2.47,2.32$ & 3.78 & $2.06,2.52$ & 1.76 \\
\hline & 180 & 2.22 & 3.76 & 2.13 & - \\
\hline & 240 & $2.86,2.61$ & 3.44 & $1.91,2.25$ & 1.79 \\
\hline & 300 & 2.19 & 3.96 & 1.92 & - \\
\hline
\end{tabular}


Fig. 6 Apatite thin films on partially protonated quartz surfaces: (a) $75 \%$ at a rotation of $120^{\circ}$, (b) $50 \%$ at $120^{\circ}$ and (c)

$25 \%$ at $240^{\circ}(\mathrm{Ca}=$ mid grey,

$\mathrm{O}=$ black, $\mathrm{F}=$ pale grey, $\mathrm{PO}_{4}$ groups displayed as tetrahedra, $\mathrm{Si}=$ pale grey, $\mathrm{O}=$ black, $\mathrm{H}=$ white)

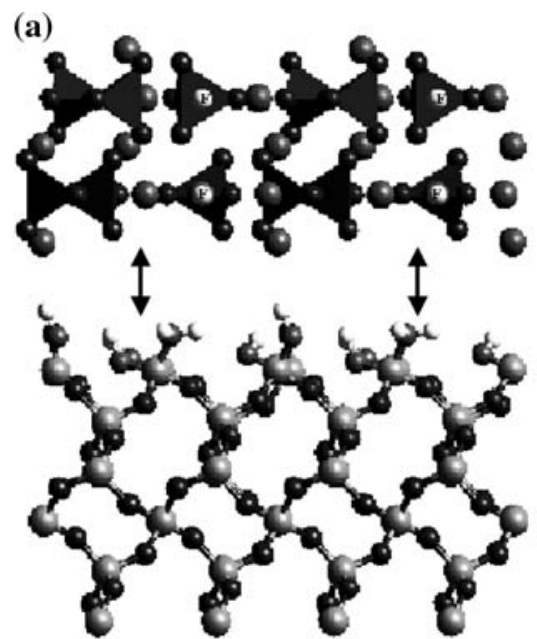

Single layer before minimisation

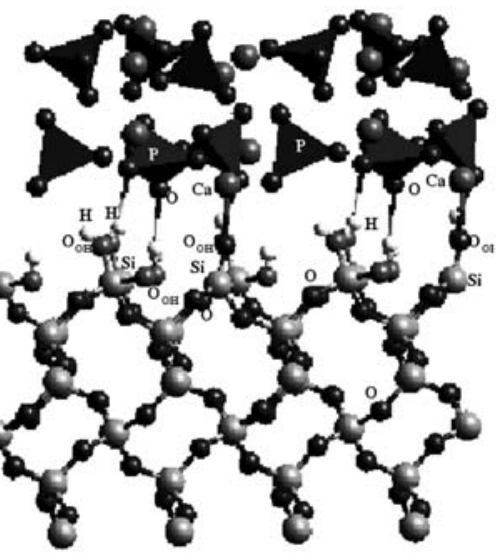

Single layer after minimisation

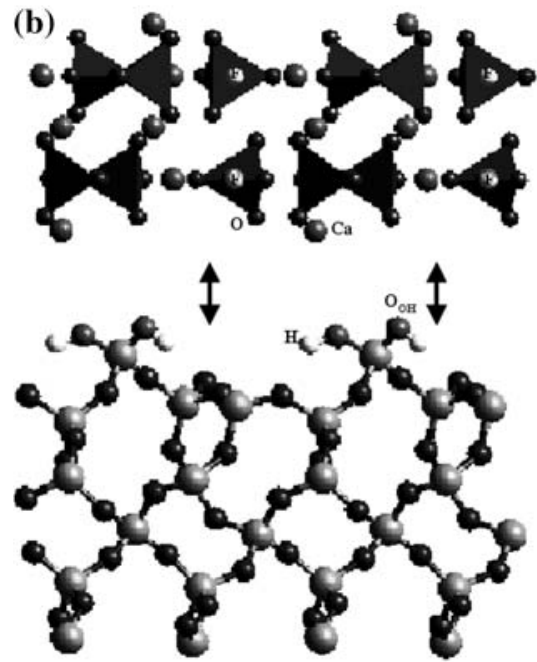

Single layer before minimisation

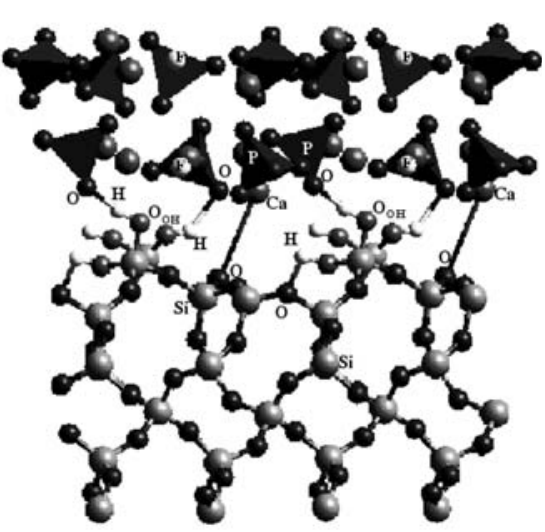

Single layer after minimisation

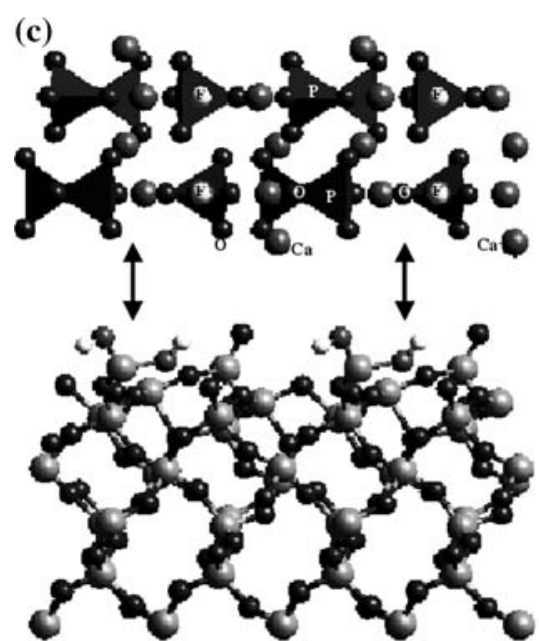

Single layer before minimisation

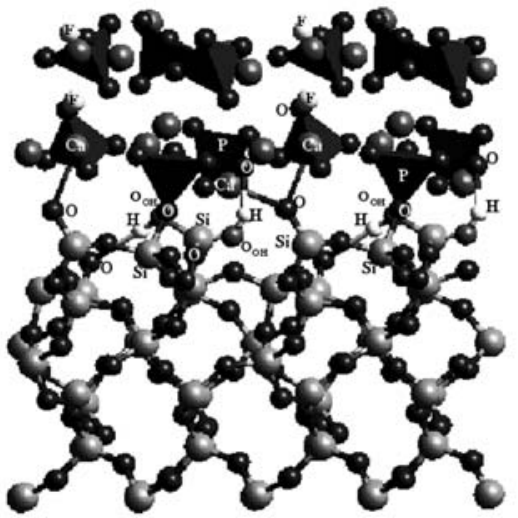

Single layer after minimisation 
Like the $75 \%$ protonated surface, the $25 \%$ protonated surface (density of silanol groups $=2.5 \mathrm{~nm}^{-2}$ ) also contains one dangling oxygen bond and one three-coordinated silicon atom. The energetically preferred apatite/silica interface formed at this substrate surface is shown in Fig. 6c, and we see that it is different from the previous interfaces described above, in that the $\mathrm{PO}_{4}$ groups have rotated significantly in the apatite film to allow their oxygen atoms to form bonds with the Q3 silicon atoms at $1.74 \AA$, saturating the $\mathrm{Si}$ atom's coordination to its bulk value of four. Hydrogen bonds to apatite oxygen atoms are formed at $1.98 \AA$ and two calcium atoms interact with the singly coordinated oxygen atom on the silica surface at fairly long $\mathrm{Ca}-\mathrm{O}$ distances of 2.47 and $2.51 \AA$. In the energetically less favourable rotations, only one $\mathrm{Ca}-\mathrm{O}$ bond is formed at a shorter bondlength of 2.22-2.27 $\AA$, but as the other interactions between the film and substrate are similar for the various rotations, the presence of two $\mathrm{Ca}-$ $\mathrm{O}_{\text {silica }}$ interactions, as well as a further fairly close $\mathrm{Ca}-\mathrm{OH}$ interaction (3.05 $\AA$ ), clearly outweighs the formation of one, stronger $\mathrm{Ca}-\mathrm{O}$ bond (plus weaker $\mathrm{Ca}-\mathrm{OH}$ interactions at 3.57-4.09 $\AA$ ).

The interfacial structures formed upon adhesion of double layers of apatite at the substrate surfaces (Table 3) are similar to those with single apatite layers. However, due to the greater thickness of the apatite films, the structure of the films is less distorted compared to the single apatite layers, where rearrangement and rotation of $\mathrm{PO}_{4}$ groups occurs more easily to maximise the substrate/film interactions (see Fig. 7). The only exception is the film attached to the $25 \%$ protonated substrate where the formation of a bond between an oxygen in the apatite layer to the Q3 silicon still causes rotation of its $\mathrm{PO}_{4}$ group near the interface. As a result of the lesser flexibility of the apatite film, some of the interactions between apatite film and silica substrate are more distant, especially the hydrogenbonded interactions. The $\mathrm{Ca}-\mathrm{O}$ interactions on the other hand are fairly similar, and often even closer (Table 3), indicating that these interactions, especially with the singly coordinated oxygen atom of the $75 \%$ and $25 \%$ protonated surfaces, are particularly important for the stability of the substrate/film interface.

\section{Adhesion energies}

We have calculated the interfacial structures and energies as a function of rotation of the thin films with respect to the substrate surfaces to ensure that we have investigated the effect of relative orientation of the film and substrate surface on the stabilities of the interfacial system. The strength of interaction between the apatite film and the substrate surface is described by the adhesion energy $\gamma_{\text {adh }}$, which is defined as follows:

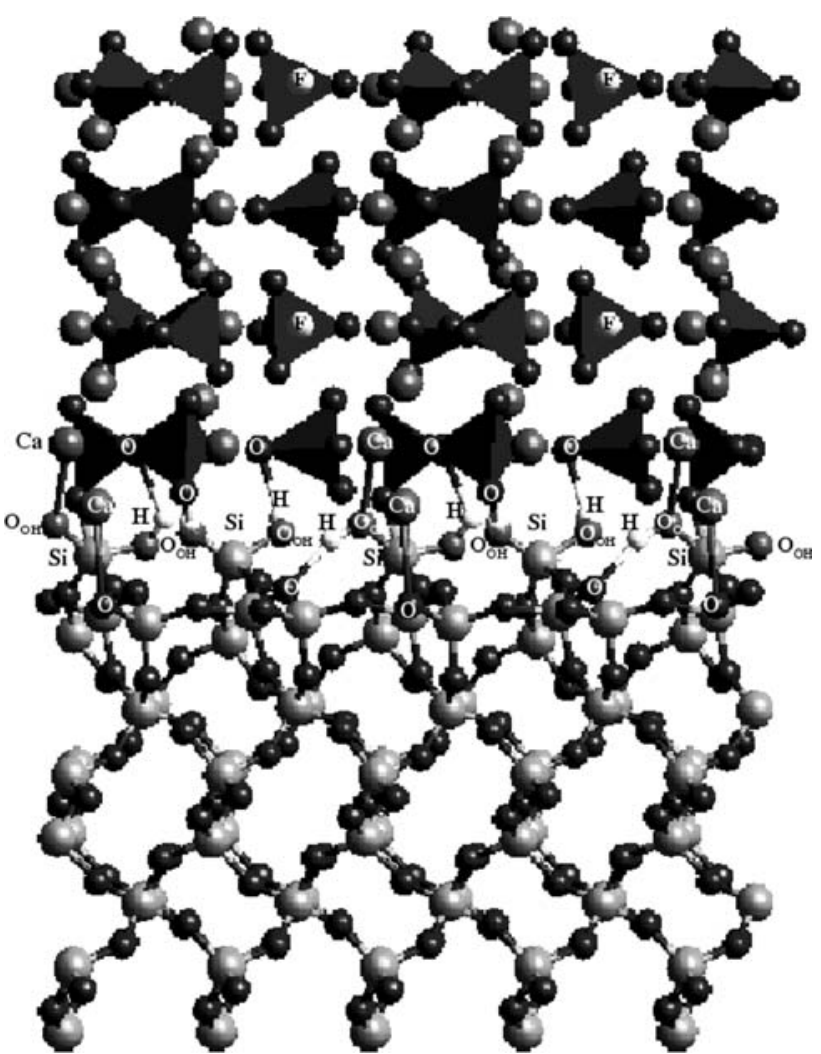

Fig. 7 Double layer of apatite film on the $50 \%$ protonated surface, showing a maximum number of interactions between the silanol groups and the apatite species $(\mathrm{Ca}=$ mid grey, $\mathrm{O}=$ black, $\mathrm{F}=$ pale grey, $\mathrm{PO}_{4}$ groups displayed as tetrahedral, $\mathrm{Si}=$ pale grey, $\mathrm{O}=$ black, $\mathrm{H}=$ white)

$\gamma_{\text {adh }}=\frac{E_{\text {int }}-\left(E_{\text {surf }, q u a r t z}+n E_{\text {apatite }}\right)}{A}$

where $E_{\text {int }}$ is the energy of the interfacial system, $E_{\text {surf,quartz }}$ is the energy of the free substrate surface, $n$ is the number of formula units of apatite of energy $E_{\text {apatite }}$ in the thin film and $A$ is the surface area of the interface. The adhesion energy is hence the energy per unit area which is expended when the apatite is attached as a thin film onto the substrate surface, where a low, positive number of $\gamma_{\text {adh }}$ thus indicates an energetically feasible interface. The adhesion energies for the attachment of apatite films of two thicknesses onto all of the substrate surfaces are listed in Table 4 (for the fully deprotonated and fully protonated substrate surfaces) and Table 5 (for the partially protonated surfaces). For the partially protonated surfaces, we have only listed the adhesion energies for the substrate surface configurations that gave the energetically most favourable interfacial adhesion energies.

If we first compare the adhesion energies of the deprotonated surface with the $\mathrm{O}-\mathrm{Si}-\mathrm{O}$ 6-rings in the surface plane with the fully protonated surface terminated by 
Table 4 Adhesion energies for apatite thin films at the deprotonated silica surface and at the fully protonated surface with silanol densities of 0 and $10 \mathrm{~nm}^{-2}$ respectively

\begin{tabular}{lllll}
\hline Rotation $^{\circ}$ & \multicolumn{2}{l}{ Adhesion energies $\left(\mathrm{J} \mathrm{m}^{-2}\right)$} & & \\
\cline { 2 - 5 } & \multicolumn{2}{l}{ De-protonated $(0001)$ surface } & & \multicolumn{2}{l}{ Fully protonated (0001) surface } \\
\cline { 2 - 5 } & Single layer & Double layer & Single layer & 1.64 \\
\hline $0 / 360$ & 0.58 & 0.83 & 1.36 & 1.63 \\
60 & 0.57 & 1.05 & 1.45 & 1.63 \\
120 & 0.57 & 0.89 & 1.37 & 1.63 \\
180 & 0.73 & 0.83 & 1.36 & 1.64 \\
240 & 0.55 & 0.82 & 1.45 & 1.63 \\
300 & 0.65 & 1.11 & & \\
\hline
\end{tabular}

Table 5 Adhesion energies for apatite thin films at partially protonated silica surfaces with surface silanol densities of $2.5,5.0$ and $7.5 \mathrm{~nm}^{-2}$

\begin{tabular}{|c|c|c|c|c|c|c|}
\hline \multirow[t]{3}{*}{ Rotation $^{\circ}$} & \multicolumn{6}{|c|}{ Adhesion energies $\left(\mathrm{J} \mathrm{m}^{-2}\right)$} \\
\hline & \multicolumn{2}{|c|}{$25 \%$ protonated surface } & \multicolumn{2}{|c|}{$50 \%$ protonated surface } & \multicolumn{2}{|c|}{$75 \%$ protonated surface } \\
\hline & Single layer & Double layer & Single layer & Double layer & Single layer & Fs \\
\hline $0 / 360$ & 1.26 & 1.52 & 1.14 & 1.40 & 1.19 & 1.46 \\
\hline 60 & 1.20 & 1.49 & 1.18 & 1.34 & 1.17 & 1.44 \\
\hline 120 & 1.06 & 1.32 & 1.04 & 1.40 & 1.16 & 1.44 \\
\hline 180 & 1.32 & 1.42 & 1.17 & 1.38 & 1.16 & 1.44 \\
\hline 240 & 1.01 & 1.56 & 1.14 & 1.22 & 1.18 & 1.46 \\
\hline 300 & 1.20 & 1.49 & 1.14 & 1.38 & 1.17 & 1.44 \\
\hline
\end{tabular}

surface silanol groups (Table 4), we immediately see, that the interfaces formed through the interaction of the apatite calcium and oxygen ions with the silicon and oxygen of the de-protonated surface are energetically more favourable (i.e. lower adhesion energy) than those formed through hydrogen-bonding to the silanol groups of the protonated surface, which interactions are clearly much weaker. We note from Table 4, that the adhesion energies fall in a fairly narrow band for the different rotations, especially for the fully protonated surface, indicating that the relative orientation of the substrate and thin film is not particularly important to the strength of interaction, probably because no chemical bonds are formed. On the de-protonated surface, the interaction between the two materials is limited to non-directional electrostatic interactions but no bonds are created as the $\mathrm{Si}$ and $\mathrm{O}$ atoms remain fully coordinated in surface $\mathrm{O}-\mathrm{Si}-\mathrm{O}$ bridges. The effect of surface protonation to form surface silanol groups is to mask the substrate surface configuration from the apatite layer. As the hydroxy groups at the quartz surface are flexible [39], they can orientate themselves to form a maximum number of hydrogen-bonded interactions with the apatite layer, whatever its orientation.

Furthermore, the adhesion energies in Table 4 show that most of the energy of formation of the interface is spent in adhesion of the first layer, while the attachment of the double layer thin films increases the adhesion energies by a relatively small amount, especially at the protonated surface where attachment of the second layer costs an extra $0.28 \mathrm{Jm}^{-2}$ at most, indicating that the formation of the initial single layer onto the substrate surface will be the rate limiting step and growth of further layers should follow. The reason for the small energetic penalty to grow the second layer of apatite is due to the interfacial structure. As we have seen in Fig. 5, the apatite layers at the interface are very regular and resemble the bulk structure of apatite. Any structural readjustment of the apatite to accommodate itself to the substrate surface occurs during the epitaxial fitting of the initial layer to the quartz substrate and hence the deposition of further apatite layers is relatively easy.

Comparing now the adhesion energies of the thin films at the partially protonated surfaces, listed in Table 5, we see immediately that the adhesion energies are much higher than those obtained at the completely unprotonated surface, even when the silica is only protonated for $25 \%$. Clearly, the presence of even a small number of hydroxy groups prohibits the formation of a closely coordinated apatite film at the silica surface. Perhaps somewhat surprisingly, where the apatite film forms direct bonds to the under-coordinated $\mathrm{Si}$ and $\mathrm{O}$ species, as is the case on the 25 and $75 \%$ 
protonated surfaces, the adhesion energy is actually higher than for the $50 \%$ protonated surface, where the interaction between apatite and silica is only through hydrogenbonding and non-bonded electrostatic interactions. We further tested this finding by calculating the adhesion energies for a thin film of apatite formed at one of the less stable $50 \%$ protonated silica surfaces, which also contained under-coordinated surface silicon and oxygen atoms. However, the adhesion energies for this system were again larger than the adhesion energies shown in Table 5 for the more stable $50 \%$ protonated surface (by up to $0.8 \mathrm{Jm}^{-2}$ ). Once again, the saturation of the dangling bonds through bonding to the apatite $\mathrm{Ca}$ and $\mathrm{O}$ atoms did not lead to more favourable adhesion energies.

\section{Conclusions}

Our comprehensive computational study of the formation of apatite films at a number of silica surfaces with varying surface densities of silanol groups suggest the following conclusions:

The adhesion of apatite is stronger to the de-protonated silica substrate rather than to any of the (partially) protonated surfaces, with the fully protonated surface leading to the weakest film/substrate interaction. The density of surface silanol groups does not have a significant effect on the strength of interaction between the silica and apatite, as the variation in adhesion energies at the partially and fully protonated substrate is small. Only complete deprotonation of the substrate leads to a significant increase in stability of the interface.

Where possible, $\mathrm{Ca}-\mathrm{O}_{\text {silica }}$ and $\mathrm{O}_{\text {apatite }}-\mathrm{Si}$ coordinations are formed in preference to $\mathrm{O}_{\text {apatite }}-\mathrm{H}$ hydrogen-bonded interactions. Although any dangling bonds present at the silica surface are saturated by interactions with $\mathrm{Ca}$ and $\mathrm{O}$ atoms in the apatite film, these interactions do not necessarily lead to more strongly bonded apatite films than those formed at the fully coordinated substrate species.

Where an equal number of surface silanol groups are present at two different substrate surfaces (i.e. different surface configurations of the $50 \%$ protonated silica surface), the most favourable apatite/silica interface is formed at the most stable substrate surface, which contains fewer dangling bonds, rather than at the surface with a greater number of under-coordinated, and hence more reactive, surface sites. The structure and stability of the substrate thus seems to play a greater rôle in the formation of a stable interface than the reactivity of the substrate surface sites.

The importance of the substrate stability is further exemplified by the fully de-protonated surface, which is a stable fully-coordinated surface, leading to the most favourable interfaces. The interfaces are particularly favourable where the absence of extensive interfacial relaxation leads to an apatite film which closely resembles the bulk apatite structure. Once the first apatite layer has been laid down on the substrate surfaces, further apatite growth is energetically not expensive, which should lead to rapid growth of the apatite phase.

Our simulations support the suggestion that apatite grows most easily on silica-containing surfaces where condensation of surface hydroxy groups has led to the formation of saturated $\mathrm{O}-\mathrm{Si}-\mathrm{O}$ bridges rather than through hydrogen-bonding to surface silanol groups. We would suggest that this is a general result, which also applies to different materials containing hydroxy groups, for example functionalised polymers which are increasingly used in bio-compatible scaffolds for tissue engineering [40]. As such, future work will include the investigation of apatite nucleation and growth at titania surfaces to investigate whether the above trends are generally applicable to other oxide materials. In addition, accurate computational models for bio-active glasses are now also available [41] and molecular dynamics simulations will be carried out to study nucleation and growth of apatite at bio-active glass surfaces to investigate the nano-scale structure and interaction of the growing apatite particles with the surface species on the less ordered glass surface and with each other.

Acknowledgements DM thanks the Royal Society, UK for a South Africa International Fellowship and NHdL thanks the Engineering and Physical Sciences Research Council, UK for an Advanced Research Fellowship and for grant no. GR/S77714/01.

\section{References}

1. D. M. SANDERS, W. B. PERSON and L. L. HENCH, Appl. Spectrosc. 26 (1972) 530

2. T. S. B. NARASARAJU and D. E. PHEBE, J. Mater. Sci. 31 (1996) 1

3. H. FUJITA, T. NAKAMURA, J. TAMURA, M. KOBAYASHI, Y. KATSURA and T. KOKUBO, J. Biomed. Mat. Res. 40 (1998) 145

4. T. KOKUBO, Mat. Res. Eng. C 25 (2005) 97

5. K. KANDORI, S. SAWAI, Y. YAMAMOTO, H. SAITO and T. ISHIKAWA, Colloids Surf. 68 (1992) 283

6. K. KANDORI, A. FUDO and T. ISHIKAWA, Phys. Chem. Chem. Phys. 2 (2000) 2015

7. S. B. CHO, F. MIYAJI, T. KOKUBO, K. NAKANISHI, N. SOGA and T. NAKAMURA, J. Mater. Sci.-Mat. in Medicine 9 (1998) 279

8. I. D. XYNOS, A. J. EDGAR, L.D.K. BUTTERY, L. L. HENCH and J. M. POLAK, Biochem. Biophys. Res. Commun. 276 (2000) 461

9. C. Y. KIM, A. E. CLARK and L. L. HENCH, J. Non-Cryst. Solids 113 (1989) 195

10. P. LI, C. OHTSUKI, T. KOKUBO, K. NAKANISHI, N. SOGA and K. De Groot J. Biomed. Mat. Res. 28 (1994) 7

11. S. B. CHO, K. NAKANISHI, T. KOKUBO, N. SOGA, C. OHTSUKI and T. NAKAMURA, J. Biomed. Mat. Res. (App Biomaterials) 33 (1996) 145 
12. D. EGLIN and C. C. PERRY, J. Bioact. Compat. Polym. 20 (2005) 437

13. A. P. Sutton and R. W. Balluffi, Interfaces in crystalline materials, Monographs on the physics and chemistry of materials, vol. 51 (Clarendon Press, Oxford, 1995)

14. G. W. WATSON, E. T. KELSEY, N. H. De LEEUW, D. J. HARRIS and S. C. PARKER, J. Chem. Soc. Faraday. Trans. 92 (1996) 433

15. D. J. HARRIS, G. W. WATSON and S. C. PARKER, Philos. Mag. A 74 (1996) 407

16. N. H. De LEEUW, S. C. PARKER, C. R. A. CATLOW and G. D. PRICE, Am. Mineral. 85 (2000) 1143

17. R. BENEDEK, D. N. SEIDMAN and C. WOODWARD, J. Phys. Condens. Matter 14 (2002) 2877

18. D. C. SAYLE, S. A. MAICANEANU, B. SLATER and C. R. A. CATLOW, J. Mater. Chem. 9 (1999) 2779

19. D. C. SAYLE, C. R. A. CATLOW, N. DULAMITA, M. J. F. HEALY, S. A. MAICANEANU, B. SLATER and G. W. WATSON, Mol. Simulat. 28 (2000) 683

20. N. H. De LEEUW, D. MKHONTO and C. R. A. CATLOW, J. Phys. Chem. B 107 (2003) 1

21. N. H. De LEEUW and D. MKONTO, Chem. Mat. 15 (2003) 1567

22. M. Born K. Huang, Dynamical Theory of Crystal Lattices (Oxford University Press, Oxford, 1954)

23. D. E. PARRY, Surf. Sci. 49 (1975) 433

24. D. E. PARRY, Surf. Sci. 54 (1976) 195

25. B. G. DICK and A. W. OVERHAUSER, Phys. Rev. 112 (1958) 90

26. M. J. SANDERS, M. LESLIE and C. R. A. CATLOW, J. Chem. Soc. Chem. Commun. (1984) 1271
27. N. H. De LEEUW, F. M. HIGGINS and S. C. PARKER, J. Phys. Chem. B 103 (1999) 1270

28. Z. DU and N. H. De LEEUW, Surf. Sci. 554 (2004) 193

29. D. MKHONTO and N. H. De LEEUW, J. Mat. Chem. 12 (2002) 2633

30. K. P. SCHRODER, J. SAUER, M. LESLIE and C. R. A. CATLOW, Chem. Phys. Lett. 188 (1992) 320

31. N. H. De LEEUW and D. MKHONTO, J. Mat. Chem. 15 (2005) 3272

32. F. C. R. BERTAUT, Acad Sci Paris 246 (1958) 3447

33. M. J. NORGETT and R. FletCHER, J. Phys. C 3 (1970) L190

34. W. A. Deer R. A. Howie J. Zussman, An introduction to the rockforming minerals, (Longman, UK, 1992)

35. J. A. L. RABONE and N. H. DE LEEUW, J. Comput. Chem. 27 (2006) 2150

36. J. C. ELLIOTT, "Structure and chemistry of the apatites and other calcium orthophosphates", Studies in inorganic chemistry vol 18 (Elsevier, 1994)

37. S. B. HENDRICKS, M. E. JEFFERSON and V. M. MOSLEY, Z.Kristall. Kristallgeom. Kristallphys. Kristallchem. 81 (1932) 352

38. Y. DUVAL, J. A. MIELCZARSKI, O. S. POKROVSKY, E. MIELCZARSKI and J. J. EHRHARDT, J. Phys. Chem. B 106 (2002) 2937

39. Z. DU and N. H. De LEEUW, Dalton Trans. 22 (2006) 2623

40. T. KAWAI, C. OHTSUKI, M. KAMITAKAHARA, M. TANIHARA, T. MIYAZAKI, Y. SAKAGUCHI and S. KONAGAYA, Key. Eng. Mater. 284-286 (2005) 505

41. A. TILOCCA, N. H. DE LEEUW, and A. N. CORMACK, Phys. Rev. B 73 (2006) 104209 